\title{
Pollen contamination in Acacia saligna: assessing the risks for sustainable agroforestry
}

\author{
M. A. Millar ${ }^{1,2,3}$ \& M. Byrne ${ }^{2,3}$ \\ ${ }^{1}$ The University of Adelaide, Australia \\ ${ }^{2}$ CRC for Plant Based Management of Dryland Salinity, Australia \\ ${ }^{3}$ Department of Environment and Conservation, Australia
}

\begin{abstract}
Species developed for sustainable agroforestry may pose risks to remnant populations of closely related species via genetic contamination. Genetic contamination and the production of hybrid progeny may threaten the health and long-term viability of remnant populations. Acacia saligna is a native Western Australian species complex selected for further development for agroforestry in the agricultural areas of southern Australia. A. saligna shows great morphological, ecological, biological and genetic variation, and will be reclassified into a number of subspecies. This research aimed to develop genetic markers and use them to assess the levels and distances of gene flow via pollen dispersal between two of the proposed subspecies of Acacia saligna. Pollen dispersal from the abundantly flowering subsp. saligna into the poorer flowering subsp. lindleyi was high (32\%). At the same site, pollen dispersal from subsp. lindleyi into subsp. saligna was much lower (14\%). Most genetic contamination from subsp. saligna into subsp. lindleyi occurred at short distances $(<300 \mathrm{~m})$ although inter-subspecific pollen dispersal was detected over large distances of around $1600 \mathrm{~m}$. The comparative levels of inter-subspecific pollen dispersal are influenced by the relative floral fecundity of the different variants. The results indicate that small remnant populations of subsp. lindleyi will be exposed to high levels of hybridisation when subsp. saligna is planted nearby for agroforestry. The effects of inter-subspecific hybridisation in A. saligna are unknown and until further investigated it is recommended as a management guideline that isolation distances of $1600 \mathrm{~m}$ or more be imposed between agroforestry plantings and native populations.

Keywords: agroforestry, pollen dispersal, species complex, inter-subspecific hybridisation, genetic contamination, microsatellites, paternity analysis, Acacia saligna, risk assessment, isolation distances.
\end{abstract}




\section{Introduction}

Species developed for sustainable agroforestry may pose risks to remnant populations of closely related species when introduced nearby. These risks include direct invasiveness into natural ecosystems, supporting increased incidences of pests, disease and feral animals, and the possibility of genetic contamination in remnant natural populations [1]. Genetic contamination, or the movement of foreign genes from non-local populations into native populations, may occur in tree species via pollen dispersal [2] and may arise in natural populations when populations of a similar species or genetically divergent populations of the same species are planted nearby. If the floral phenologies of divergent populations overlap and sufficient interfertility exist between them, gene flow via pollen transfer between the populations results in intra specific, inter-subspecific or interprovenance hybridisation and the production of hybrid progeny. The likelihood and possible impact of this scenario is receiving increasing attention, due to the threat of gene flow and hybridisation between natural populations and introduced transgenic crops [3-7].

Divergent populations may be intentionally introduced throughout the range of natural populations for agriculture or agroforestry, or through revegetation programs, and unintentionally through the spread of invasive species. In the case of agroforestry, genetic divergence between natural and introduced populations may arise through the use of non-local subspecies or non-local provenance germplasm, or selection pressure applied in breeding and domestication programs [1]. If agroforestry populations (pollen source) are large in comparison to natural remnant populations (pollen sink), levels of genetic contamination and the production of hybrid progeny may be significant.

Genetic contamination in natural populations results in one of two outcomes for hybrid progeny: heterosis or outbreeding depression, and the impacts of either may threaten the health and long-term viability of natural populations $[2,8]$. Heterosis, or hybrid vigour, occurs when hybrid fitness is enhanced relative to the parental populations, and may result in the establishment of large hybrid populations between agroforestry and remnant populations. If hybrid fitness is maintained over the generations, the natural population may be at risk from direct competition, hybrid swamping and the impacts of small population processes such as a loss of genetic diversity. Continued hybridisation may eventually result in total genetic assimilation of the typically smaller, native population via introgression. This occurs with the repeated backcrossing of hybrids to one or both of the parental populations.

The other possible outcome for hybrid progeny is outbreeding depression. This occurs when hybrid fitness is reduced relative to the parental population. In this case, the reproductive output of a native population may again be lowered to levels that threaten the population viability [9]. Pollen swamping may also be detrimental to the viability of natural populations regardless of whether hybrid progeny are produced. Seed production and recruitment within the natural population may be significantly reduced, especially in small populations $[10,11]$. 
In Australia, the majority of the once extensive woody vegetation has been cleared for agricultural production and there is an urgent need to revegetate with native perennials. Revegetation is required in order to halt the degradation of biological integrity, restore the hydrological balance and mitigate increasing levels of salinisation in the land and waterways. A number of native Australian species are being developed for use in revegetating the agricultural areas of southern Australia via agroforestry; however, there is some risk to remnant populations via genetic contamination with large-scale agroforestry. The potential for genetic contamination and hybridisation between non-local populations of native species needs to be considered to ensure that revegetation systems are environmentally sustainable and pose no further risks to biodiversity. The potential for genetic contamination from large-scale agroforestry crops must be evaluated within a risk management framework that requires comprehensive risk assessment [8, 12].

Acacia saligna is a native Western Australian species complex selected for further development for agroforestry, as a short rotation phase or coppice crop, in the low rainfall areas of southern Australia [13, 14]. A. saligna has been recognised as a species complex that shows great morphological, ecological, biological and genetic variation. The species complex has been partitioned into a number of subspecies to be formally taxonomically described. Little is known about the mating system, patterns of gene flow via pollen dispersal, and levels of genetic contamination that can be expected within and between populations of the different subspecies of A. saligna. These parameters can be estimated through paternity analysis using genetic markers such as microsatellites. Microsatellite markers are suitable for paternity analysis studies as they are highly polymorphic, codominant, considered selectively neutral, and can be amplified from small amounts of genomic DNA.

As part of a larger process of assessing the risk posed by large-scale utilisation of $A$. saligna as an agroforestry crop to natural remnant populations of A. saligna, we developed and screened microsatellite markers for use in $A$. saligna [15].

The markers were then used for paternity analysis to investigate pollen dispersal patterns and levels of genetic contamination, via inter-subspecific hybridisation, for two of the proposed subspecies of $A$. saligna. The results of this work will be used in developing risk management protocols that ensure the environmentally sustainable use of $A$. saligna for agroforestry throughout southern Australia.

\section{Materials and methods}

\subsection{Study species}

Acacia saligna is a leguminous bushy shrub or tree, naturally distributed over southwestern Australia where it experiences a Mediterranean climate. Trees grow to 2-10 $\mathrm{m}$ at maturity and live for up to twenty years under favourable conditions [16]. Trees bear hermaphroditic, many flowered, globular 
inflorescences and produce flat pods containing small, hard, black seeds [17]. The species complex consists of four main variants to be formally described as subspecies (McDonald MW and Maslin BR ms): illustrated in Figure 1.

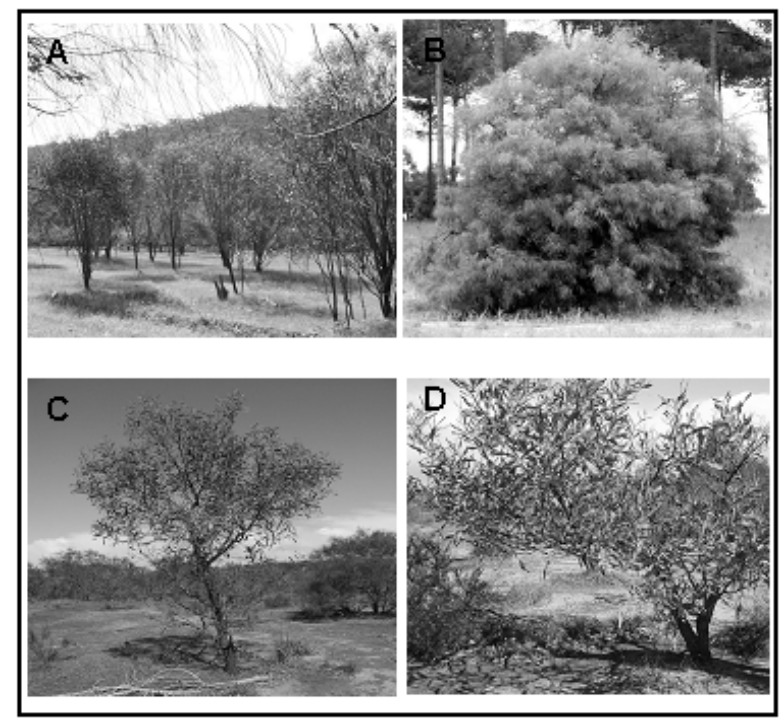

Figure 1: Morphological variants of Acacia saligna showing mature specimens of subspecies (A) lindleyi (B) saligna (C) stolonifera and (D) pruinescens.

Acacia saligna subsp. saligna is native to the coastal areas around Perth and on the south coast; it shows the greatest biomass and floral fecundity of the four subspecies. This subspecies has been commonly used as an ornamental and in revegetation programs, and is likely to be the variant most commonly utilised for agroforestry. Acacia saligna subsp. lindleyi is the most widespread of the subspecies and occurs across the inland "wheat and sheep belt" area of Western Australia, which is the target area for revegetation. It has a spindly form with little biomass and limited terminal flowering. Acacia saligna subsp. stolonifera has a natural distribution in the forest areas to the south-west of the range of subsp. lindleyi. Subsp. pruinescens occurs over a restricted area and shows some genetic affinity with subsp. saligna.

\subsection{Study site and sample collection}

The study site consists of a planted stand of 107 trees of $A$. saligna subsp. saligna within the natural distribution of subsp. lindleyi, trees of which occur as roadside remnants at varying distances from the planted stand (Figure 2). The planted $A$. saligna stand occupies an area of approximately 0.55 hectares at the intersection of two roads. The closest subsp. lindleyi trees are approximately 25 $\mathrm{m}$ from the edge of the planted stand. This remnant consists of several hundred 
individuals, although the majority of these were not reproductively mature at the time of sampling. Trees extend away from the planted stand, along a road verge, in a westerly direction, where they become less abundant, eventually occurring as individuals at a maximum distance of $300 \mathrm{~m}$ from the stand. Further remnant subsp. lindleyi trees are present along the roadside in a south-easterly direction, where they occur sporadically in two main patches approximately 900 and 1500 $\mathrm{m}$ from the stand. Many of the trees in the remnant patches were juvenile and fecundity of the adult trees was highly variable.

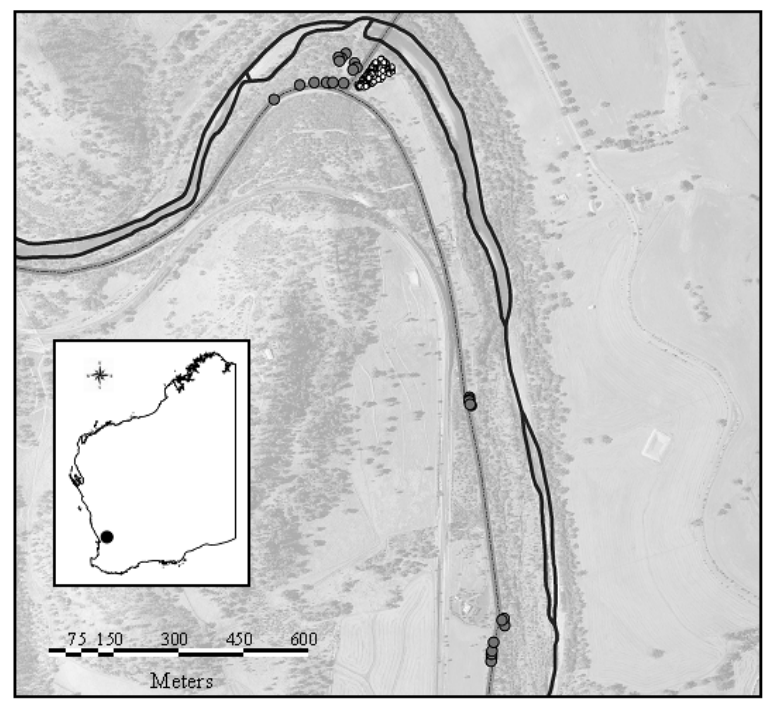

Figure 2: $\quad$ Map of the study site showing locations of sampled trees of Acacia saligna. Larger grey circles represent sampled trees of subsp. lindleyi; smaller white circles represent sampled trees of subsp. saligna in the planted stand; dark lines represent the Avon River; light grey broken lines represent roadways.

Mature phyllode material was collected from all trees of subsp. saligna within the planted stand and from 29 trees of subsp. lindleyi. Open pollinated seed was sampled from 10 maternal trees of $A$. saligna subsp. saligna chosen at random from within the stand and from each of the selected 29 trees of subsp. lindleyi. As seed set was poor in subsp. lindleyi, trees with the largest seed crops were chosen for sampling. All trees of subsp. saligna and the 29 maternal trees of subsp. lindleyi were mapped using a differential global positioning satellite system. Seed from each tree was extracted from dry pods and bulked, sterilised, left to imbibe overnight and planted. No seed germinated for one of the maternal trees of subsp. saligna and for two of the trees of subsp. lindleyi, so seed crops were analysed for nine and 27 maternal trees respectively. Genomic DNA was extracted from phyllodes of the adult trees using a modified cetyltrimethyl 
ammonium bromide (CTAB) extraction method [18], with the addition of $0.1 \mathrm{M}$ sodium sulphite to the extraction and wash buffers [19], and from germinated seedlings using a modified Doyle and Doyle method [20].

Two microsatellite markers developed for A. saligna and three microsatellite markers developed for $A$. mangium [21] produced suitable cross amplification in A. saligna. Genotypes of all A. saligna subsp. saligna trees in the planted stand and progeny arrays for nine families consisting of 11-22 seedlings (186 in total), and of 29 A. saligna subsp. lindleyi trees and progeny arrays for 27 families consisting of $1-25$ seedlings (396 in total), were determined for the five microsatellite loci. The size of PCR products was determined by automated fluorescent scanning detection using an Applied Biosystems 3730 DNA Analyser (Applied Biosystems, Foster City CA, USA).

\subsection{Data analysis}

Paternity assignment was conducted using maximum likelihood methods implemented in CERVUS 2.0 [22]. A 95\% criterion was used for assignment, with mismatch at one locus allowed. Since geitonogamous pollination is possible, assignment of paternity to the mother plant was assumed to be due to selfing. The patterns of pollen dispersal within and between trees of subsp. saligna and trees of subsp. lindleyi were evaluated by determining the distance between mother and pollen source for each of the progeny.

\section{Results}

Using the five loci, the majority (93.5\%) of subsp. saligna progeny were assigned a most likely father from either trees of subsp. saligna or the sampled subsp. lindleyi trees. The majority of subsp. saligna progeny $(86 \%)$ were sired by pollen from within the stand of subsp. saligna. Fourteen subsp. saligna progeny $(7.5 \%)$ were assigned a most likely father from the sampled subsp. lindleyi trees. Most likely fathers were undefined for twelve subsp. saligna progeny $(6.5 \%)$ and these were assumed sired by unsampled trees of the background population of subsp. lindleyi. The rate of pollen contamination into the subsp. saligna stand is the percentage of progeny whose paternity was not assigned to subsp. saligna trees. This inter-subspecific gene flow totalled $14 \%$ [15]. Genetic contamination rates varied among maternal trees of subsp. saligna within the stand (0 to $32 \%$ ). Of the 29 genotyped trees of A. saligna subsp. lindleyi, $10(34.5 \%)$ were assigned as fathers of one or more progeny of maternal trees in the planted stand of subsp. A. saligna. Inter-subspecific pollination events occurred over a range of distances from $5 \mathrm{~m}$ to $1566 \mathrm{~m}$ with an average pollen dispersal distance of $666 \mathrm{~m}$.

A high percentage of progeny (96.5\%) of subsp. lindleyi trees were assigned a most likely father from sampled trees of either subsp. saligna or subsp. lindleyi. Most likely fathers were undefined for fourteen subsp. lindleyi progeny $(3.5 \%)$ and these were assumed sired by unsampled trees of the background population of subsp. lindleyi. The rate of pollen contamination in subsp. lindleyi trees is the 
percentage of subsp. lindleyi progeny assigned a most likely father from trees of subsp. saligna and totalled $32 \%$ (126 progeny) [23]. Inter-subspecific hybridisation in subsp. lindleyi was highly variable among maternal trees ( 0 to $100 \%$ ) although this was not related to distance from the planted stand. Of the 107 trees of subsp. saligna, 45 (42\%) were assigned as fathers of one or more progeny in the sampled seed crops of subsp. lindleyi trees. Inter-subspecific pollination distances ranged from $42 \mathrm{~m}$ to $1607 \mathrm{~m}$ for subsp. lindleyi progeny.

\section{Conclusions}

Inter-subspecific hybridisation from a planted stand of trees of subsp. saligna was considerable for remnant roadside populations of subsp. lindleyi, and accounted for nearly one-third (32\%) of all outcrossed progeny of lindleyi trees. At the same site, pollen dispersal from subsp. lindleyi into subsp. saligna was much lower (14\%). These results show that genetic contamination between the subspecies of $A$. saligna will be an issue for the sustainable use of the species as an agroforestry crop throughout its natural range in southern Western Australia. Remnant roadside populations of subsp. lindleyi may be at risk of high levels of inter-subspecific hybridisation with introduced populations of subsp. saligna throughout the wheatbelt of Western Australia.

The disparity in inter-subspecific hybridisation between the two subspecies of A. saligna is likely due to differences in the total amount of pollen produced by each subspecies. Pollen production is influenced by the size of a population and its floral density [24]. Small populations are likely to experience a relatively large proportion of pollen immigration compared to larger populations and pollen immigration will increase in remnant populations as the introduced populations increase in size. Populations with poor flowering and pollen production are also likely to experience a relatively large proportion of pollen immigration compared to populations that are more fecund. Acacia saligna subsp. lindleyi has low floral fecundity as it has a spindly form, produces relatively few terminally located flowers and shows low seed set. In contrast, subsp. saligna shows the greatest biomass, floral density, and seed set of all four subspecies [25]. The disparity in floral fecundity between the two subspecies is noticeable at the study site where it would result in trees of subsp. saligna producing substantially more pollen in comparison to trees of subsp. lindleyi. Pollen production may also be affected by the age composition of populations at the study site. All trees in the planted stand were mature and flowered profusely in 2005, while the remnant populations were comprised of trees of various ages, including many juveniles that produced relatively few flowers and little pollen. This disparity in relative pollen production would lead to a greater contaminant pollen source for subsp. lindleyi, at the same time as a greater non-contaminant pollen source for subsp. saligna, and have the effect of both increasing intersubspecific hybridisation in subsp. lindleyi and decreasing it in subsp. saligna. The disparity in relative pollen production results in greater genetic contamination in subsp. lindleyi trees despite the greater number of trees of this subspecies at the study site. While the two subspecies rarely occur in sympatry 
under natural conditions, there is a high likelihood that large populations of subsp. saligna will be planted throughout the natural range of subsp. lindleyi for revegetation purposes. These results show that high levels of genetic contamination can be expected in remnant populations from plantings of subsp. saligna once trees reach maturity.

Most genetic contamination from subsp. saligna into remnant trees of subsp. lindleyi occurred at short distances of less than $300 \mathrm{~m}$ although significant levels of inter-subspecific pollen dispersal were detected over large distances of up to $1566 \mathrm{~m}$. Inter-subspecific genetic contamination in trees of subsp. saligna from pollen from subsp. lindleyi trees was also detected over long distances of up to $1607 \mathrm{~m}$. The results indicate that while the majority of inter-subspecific pollen contamination from introduced plantings is likely to occur over short distances, substantial amounts of inter-subspecific hybridisation may occur even when introduced populations are located at least $1.5 \mathrm{~km}$ away.

At present, the impacts of inter-subspecific gene flow and the fitness of hybrid progeny relative to parental genotypes have not been assessed for $A$. saligna. The impacts of outbreeding depression are highly unpredictable for given taxa, but adverse effects may occur even when levels of inter-subspecific gene flow are low [26]. Assessment of outbreeding depression in hybrid progeny in $A$. saligna will require fitness measurements over the entire life cycle of hybrid progeny, and extension of hybridisation studies beyond the first generation to include backcross as well as $\mathrm{F}_{2}$ hybrids. The likelihood, and the long-term genetic and ecological consequences, of introgression in A. saligna are also unknown and require investigation.

This study demonstrates that introduced plantings of tree species that maintain extensive levels of long distance gene flow, may pose some risk via pollen dispersal into genetically divergent natural populations. This risk can be reduced through cultural management practices, such as restricting germplasm used for introduced populations to that with flowering times that do not overlap with those of natural populations or harvesting trees planted for agroforestry before flowering and pollen production commences. In A. saligna, the flowering times of all four subspecies are slightly different, but do overlap so the first option may be impossible to implement in the short term. Selection for early flowering genotypes in subsp. saligna, which has the earliest flowering of the subspecies, may result in reduced overlap in flowering times among the subspecies. The second option of harvesting before floral maturity may be problematic for long-lived species however A. saligna is being promoted as a short rotation coppice crop [27] thus may be harvested before trees are old enough for flowering and pollen production to commence.

The most reliable short-term practice to limit pollen-mediated gene flow in of A. saligna may include isolation of agroforestry crops from small natural populations by distance or by the use of barrier or guard rows. Guard rows are comprised of an alternative species and used to surround crops to reduce the physical movement of pollen and 'trap' pollinators thus reducing their movement directly from the crop. The effectiveness of guard rows has not been investigated at this stage; therefore, the most effective option may be isolation. 
Significant levels of inter-subspecific pollen dispersal from subsp. saligna into subsp. lindleyi was detected over large and isolation distances greater than 1500 $\mathrm{m}$ are recommended to prevent significant levels of gene flow into natural populations.

\section{References}

[1] Byrne, M. \& Millar, M.A., Genetic systems and issues in the development of woody perennials for revegetation. Proceedings of the Conference Salinity Solutions: Working with Science and Society, eds. A. Ridley, et al., CRC for Plant-Based Management of Dryland Salinity: Bendigo, Victoria, pp. 1-5, 2004.

[2] Arnold, M., Natural hybridisation as an evolutionary process. Annual Review of Ecology and Systematics, 23, pp. 237-261, 1992.

[3] Armstrong, T., Fitzjohn, R., Newstrom, L., Wilton, A. \& Lee, G., Transgene escape: what potential for crop-wild hybridisation? Molecular Ecology, 14(1), pp. 2111-2123, 2005.

[4] Hails, R.S., Genetically modified plants - the debate continues. Trends in Ecology \& Evolution, 15(1), pp. 14-18, 2000.

[5] James, R., Difazio, S., Brunner, A. \& Strauss, S., Environmental effects of genetically engineered woody biomass crops. Biomass and Bioenergy, 14(4), pp. 403-414, 1998.

[6] Raybould, A.F., Transgenes and agriculture - going with the flow. Trends in Plant Science, 4(7), pp. 247-248, 1999.

[7] Raybould, A.F. \& Gray, A.J., Will hybrids of genetically modified crops invade natural communities. Trends in Ecology \& Evolution, 9, pp. 85-89, 1994.

[8] Ellstrand, N., Gene flow by pollen: implications for plant conservation genetics. OIKOS, 63(1), pp. 77-86, 1992.

[9] Rhymer, J.M. \& Simberloff, D., Extinction by hybridisation and introgression. Annual Review of Ecology and Systematics, 27, pp. 83-109, 1996.

[10] Wolf, D.E., Takebayashi, N. \& Rieseberg, L.H., Predicting the risk of extinction through hybridisation. Conservation Biology, 15(4), pp. 10391053, 2001.

[11] Young, A., Boyle, T. \& Brown, A., The population genetic consequences of habitat fragmentation for plants. Trends in Ecology \& Evolution, 11, pp. 413-418, 1996.

[12] Potts, B.M., Barbour, R.C., Hingston, A.B. \& Vaillancourt, R.E., TURNER REVIEW No. 6 Genetic pollution of native eucalypt gene pools - identifying the risks. Australian Journal of Botany, 51(1), pp. 1-25, 2003.

[13] Hobbs, T., et al., FloraSearch Species Profiles - Low rainfall farm forestry options for southern Australia. RIRDC Report, Rural Industries Research and Development Corporation, Adelaide, 2006 
[14] Olsen, G., Cooper, D., Carslake, J., Huxtable, D. \& Bartle, J., Search Project Report. NHT project number 973849, Final report for NHT Project 973849, National Heritage Trust, Western Australian Department of Conservation and Land Management, Perth Western Australia, 2004

[15] Millar, M.A., Byrne, M., Nuberg, I. \& Sedgley, M., High outcrossing and random pollen dispersal in a planted stand of Acacia saligna subsp. saligna revealed by paternity analysis using microsatellites. Tree Genetics and Genomes, submitted, 2007.

[16] Fox, J.E.D., A review of the ecological characteristics of Acacia saligna (Labill.) H. Wendl. Mulga Research Centre Journal, 12, pp. 39-55, 1995.

[17] Maslin, B., Acacia saligna. Flora of Australia Volume11A Mimosaceae Acacia Part 1, Australian Biological Resources Study, CSIRO Publishing: pp. 416-418, 2001.

[18] Byrne, M., Moran, G. \& Tibbits, W., Restriction map and maternal inheritance of chloroplast DNA in Eucalyptus nitens. Heredity, 84, pp. 218-220, 1993.

[19] Byrne, M., Macdonald, B. \& Francki, M., Incorporation of sodium sulfite into extraction protocol minimizes degradation of Acacia DNA. BioTechniques, 30(4), pp. 742-748, 2001.

[20] Doyle, J. \& Doyle, J., Isolation of plant DNA from fresh tissue. Focus, 12, pp. 13-15, 1990.

[21] Butcher, P., Decroocq, S., Gray, Y. \& Moran, G., Development, inheritance and cross-species amplification of microsatellite markers from Acacia mangium. Theoretical and Applied Genetics, 101, pp. 1282-1290, 2000 .

[22] Marshall, T., Slate, J., Kruuk, L. \& Pemberton, J., Statistical confidence for likelihood-based paternity inference in natural populations. Molecular Ecology, 7(5), pp. 639-655, 1998.

[23] Millar, M.A., Byrne, M., Nuberg, I. \& Sedgley, M., Long distance intersubspecific gene flow detected by paternity analysis in remnant Acacia saligna (Mimosaceae). Molecular Ecology, submitted, 2007.

[24] Kwak, M., Velterop, O. \& VanAndel, J., Pollen and gene flow in fragmented habitats. Applied Vegetation Science, 1(1), pp. 37-54, 1998.

[25] George, N., Koojong (Acacia saligna), a species with potential as a perennial forage for dryland salinity management - genetic variation, feed quality and reproductive biology. $\mathrm{PhD}$ Thesis, School of Plant Biology, University of Western Australia, Perth, 2005.

[26] Edmands, S. \& Timmerman, C., Modelling factors affecting the severity of outbreeding depression. Conservation Biology, 17(17), pp. 883-892, 2003.

[27] Bartle, J., Cooper, D., Olsen, G. \& Carslake, J., Acacia species as largescale crop plants in the Western Australian Wheatbelt. Conservation Science Western Australia, 4(3), pp. 96-108, 2002. 